\title{
A política de alimentação escolar em tempos de pandemia
}

\author{
The school food policy in times of pandemic
}

La política de alimentos escolares em tiempos de pandemia

\begin{abstract}
Resumo
Introdução: A alimentação compõe o conjunto dos "Direitos Sociais" previstos na Constituição Federal de 1988, sendo um dever do Estado a sua garantia. O Programa Nacional de Alimentação Escolar (PNAE) efetiva o dever do Estado com a educação nesse quesito da alimentação. Mediante a situação de pandemia do COVID-19 foram publicados atos normativos alterando as legislações do PNAE, de caráter excepcional enquanto durar o período de calamidade pública, para dar a continuidade na execução da política e na oferta do direito à alimentação aos estudantes. Metodologia: Estudo de revisão de literatura. Objetivo: Este trabalho busca apresentar e discutir a política pública do PNAE no seu contexto histórico e em tempos de pandemia. Resultados e discussão: Uma exposição do contexto histórico da construção da política e sua situação de execução durante esse período pandêmico. Conclusão: A elaboração desta revisão pode contribuir para a compreensão da política e ressaltar a importância dela no contexto educacional e social do país.
\end{abstract}

Palavras-chave: PNAE; COVID-19; Educação básica.

\begin{abstract}
Introduction: Food is part of the set of "Social Rights" provided for in the Federal Constitution of 1988, and its guarantee is a duty of the State. The National School Feeding Program (PNAE) fulfills the State's duty with education in this matter of food. Due to the COVID-19 pandemic situation, normative acts were published altering the PNAE legislation, of an exceptional nature as long as the public calamity lasts, in order to continue implementing the policy and offering the right to food to students. Methodology: A literature review study. Objective: This work seeks to present and discuss the PNAE public policy in its historical context and in times of pandemic. Results and discussion: An exposition of the historical context of policy construction and its implementation situation during this pandemic period. Conclusion: The elaboration of this review can contribute to the understanding of the policy and highlight its importance in the educational and social context of the country.
\end{abstract}

Keywords: PNAE; COVID-19; Basic education.

\section{Resumen}

Introducción: La alimentación forma parte del conjunto de "Derechos Sociales" previstos en la Constitución Federal de 1988, y su garantía es un deber del Estado. El Programa Nacional de Alimentación Escolar (PNAE) cumple con el deber del Estado con la educación en esta materia alimentaria. Debido a la situación de la pandemia COVID-19, se publicaron actos normativos que alteraron la legislación del PNAE, de carácter excepcional, mientras dure la calamidad pública, con el fin de seguir implementando la política y ofreciendo el derecho a la alimentación a los estudiantes. Metodología: Estudio de revisión de la literatura. Objetivo: Este trabajo busca presentar y discutir la política pública del PNAE en su contexto histórico y en tiempos de pandemia. Resultados y discusión: Una exposición del contexto histórico de la construcción de políticas y su situación de implementación durante este período pandémico. Conclusión: La elaboración de esta revisión puede contribuir a la comprensión de la política y resaltar su importancia en el contexto educativo y social del país.

Palabras clave: PNAE; COVID-19; Educación básica. 


\section{Introdução}

A alimentação compõe o conjunto dos "Direitos Sociais" previstos na Constituição Federal de 1988, sendo um dever do Estado a sua garantia. Especificamente, no Art. 208 enfatiza o dever do Estado com a educação e traz que este será efetivado mediante o atendimento ao estudante com programas suplementares no qual inclui a alimentação.

Art. 208: O dever do Estado com a educação será efetivado mediante a garantia de: II- atendimento ao educando, em todas as etapas da educação básica, por meio de programas suplementares de material didático escolar, transporte, alimentação e assistência à saúde (Brasil, 1988. Grifo nosso).

A efetivação do dever do Estado com a educação ocorre por meio da política pública do Programa Nacional de Alimentação Escolar (PNAE), este que é o mais antigo programa de alimentação escolar do Estado brasileiro, sendo considerado um dos maiores e mais abrangentes do mundo no que se refere ao atendimento universal aos estudantes da educação básica e de garantia do direito humano à alimentação adequada e saudável.

O direito humano à alimentação adequada (DHAA) ficou explícito na Lei Orgânica de Segurança Alimentar e Nutricional - LOSAN (Lei $\left.{ }^{\circ} 11.346 / 2006\right)$, em seu Art. $3^{\circ}$, descreve SAN como sendo:

A realização do direito de todos ao acesso regular e permanente a alimentos de qualidade, em quantidade suficiente, sem comprometer o acesso a outras necessidades essenciais, tendo como base práticas alimentares promotoras de saúde que respeitem a diversidade cultural e que seja ambiental, cultural, econômica e socialmente sustentáveis (Brasil, 2006).

Com a situação de calamidade pública estabelecida no Brasil pela Portaria GM/MS no 188 de 03/02/2020 e com a suspensão das atividades presenciais nas instituições de ensino, iniciou-se os desafios de como dar continuidade na oferta do programa e não comprometer o acesso dos estudantes à alimentação escolar.

Como medida de garantir esse direito a alimentação e manter o dever do Estado com a educação, o governo federal por meio da Lei $n^{\circ} 13.987$ de 07/04/2020, alterou a legislação do programa na qual autorizou, excepcionalmente durante o período de calamidade pandêmica, a distribuição de gêneros alimentícios aos estudantes e/ou responsáveis (Brasil, 2020).

A partir desse momento a oferta da política aos estudantes, em sua maioria, passou a ser mediante o recebimento desses kits de alimentação (cesta básica), algumas instituições optaram pela oferta de refeições diárias (para viagem).

Amorim, et al., (2020) retrata que a oferta de refeições tende a ter um custo unitário mais baixo e podem ser oferecidas diariamente para os estudantes, mas demandam a mobilização diária da instituição no preparo dos alimentos e do estudante e/ou responsável. Já os kits de alimentos podem ser oferecidos semanal ou mensalmente, porém, seu custo tende a ser mais alto, tornando-se um fator restritivo tanto para a qualidade e a quantidade dos alimentos ofertados quanto para a quantidade de estudantes que podem ser atendidos.

\section{Metodologia}

Trata-se de um estudo de revisão de literatura, de abordagem qualitativa, de natureza teórica, que combina elementos da pesquisa exploratória e descritiva, envolvendo em seus procedimentos a pesquisa bibliográfica. Para elaboração do trabalho, foram utilizados artigos científicos disponibilizados nas principais plataformas online e demais documentos que abarcam diferentes áreas, como educação, sociologia e saúde, caracterizando a pesquisa documental.

De acordo com Kroche (2011) a pesquisa bibliográfica se desenvolve tentando explicar um problema, na qual o investigador levantará o conhecimento disponível na área, identificando as teorias produzidas, analisando-as e avaliando sua 
contribuição para auxiliar a compreender ou explicar o problema objeto da investigação.

A pesquisa bibliográfica faz uso de fontes constituídas por material já elaborado, formado basicamente por livros e artigos científicos localizados em bibliotecas físicas ou online e a pesquisa documental se beneficia de fontes mais diversificadas e dispersas, sem tratamento analítico, como: jornais, revistas, relatórios, documentos oficiais, etc (Fonseca, 2002).

\section{Resultados e Discussão}

\subsection{Contexto histórico e a essência do PNAE}

Esta política pública teve o seu surgimento na década de 40 quando se iniciaram as primeiras discussões a respeito de fornecimento de alimentação escolar, mediante a apresentação de projetos a respeito da fome e desnutrição no Brasil pelo Instituto Nacional de Nutrição, porém, por falta de recursos públicos não se teve efetividade dessas discussões na época.

A efetivação de oferta de alimentação escolar veio a ocorrer somente na década de 50, quando foi elaborado um Plano Nacional de Alimentação e Nutrição, denominado Conjuntura Alimentar e o Problema da Nutrição no Brasil, e por meio deste se estruturou pela primeira vez um programa de merenda escolar em âmbito nacional sob a responsabilidade pública, porém, contava com o financiamento externo para sua execução do Fundo Internacional de Socorro à Infância (FISI), atual Unicef, deste plano original somente o programa de alimentação escolar sobreviveu.

Foi instituída a Campanha de Merenda Escolar (CME) em 1955 por meio do Decreto no 37.106/1955, qual era gerenciada pelo Departamento Nacional de Educação do Ministério da Educação, e possuía convênios com a FISI e outros organismos internacionais, esta campanha distribuía gêneros somente para alguns municípios carentes, ou seja, não tinha abrangência nacional. Em 1956 o Decreto no 39.007/1956 alterou a nomenclatura para Campanha Nacional de Merenda Escolar (CNME) com a intenção de promover o atendimento em âmbito nacional.

No ano de 1965, ocorreu a alteração na nomenclatura da CNME para Campanha Nacional de Alimentação Escolar (CNAE) pelo Decreto $n^{\circ} 56.886 / 1965$, este decreto também acrescentou a extensão dos programas de assistência e educação alimentar às instituições gratuitas de educação pré-primária, supletiva e de grau médio, mantendo os convênios de financiamentos externos para a execução da campanha. A CNAE fazia parte do II Programa Nacional de Alimentação e Nutrição no Brasil, em 1979 passou a denominar-se Programa Nacional de Alimentação Escolar (PNAE).

Com a instituição da Constituição Federal do Brasil em 1988 assegurou o direito à alimentação escolar a todos os estudantes do ensino fundamental, por meio de programa suplementar de alimentação escolar tendo que ser executado pelos governos federal, estaduais e municipais.

O programa era executado de forma centralizada pelo governo federal até 1993, assim o órgão gerenciador planejava os cardápios, adquiriam os gêneros por processo licitatório, contratava laboratórios especializados para efetuar o controle de qualidade e ainda se responsabilizava pela distribuição dos alimentos em todo o território nacional. Em 1994, por meio da Lei

$\mathrm{n}^{\circ}$ 8.913/1994, a execução do programa foi descentralizado mediante a celebração de convênios com os municípios e as secretarias de educação estaduais e do Distrito Federal. Com a descentralização dos recursos da alimentação escolar proporcionou a autonomia aos executores e o incentivo para a aquisição de gêneros alimentícios no comércio local, assim incentivando a inserção de pequenas empresas, fomentando a agricultura e a pecuária para o fornecimento dos alimentos básicos, in natura e regionais.

Em 1998 o gerenciamento desse programa passou a ser realizado pelo Fundo Nacional de Desenvolvimento da Educação (FNDE), autarquia vinculada ao Ministério da Educação, qual consolidou essa descentralização com a Medida 
Provisória $\mathrm{n}^{\circ}$ 1.784/1998, em que, além do repasse direto a todos os municípios e secretarias de educação, a transferência passou a ser feita automaticamente, sem a necessidade de celebração de convênios ou quaisquer outros instrumentos similares, permitindo maior agilidade ao processo. Esse novo modelo de gestão, permite aos executores o planejamento das aquisições dos gêneros alimentícios de modo a assegurar a oferta da merenda escolar durante todo o ano letivo.

O programa foi regido pela Lei no 8.913/1994 até o ano de 2009, quando os atos normativos da alimentação escolar passaram por revisões e as atualizações das legislações foram sancionadas pela Lei n ${ }^{\circ} 11.947$ de 16/06/2009, a qual rege o programa atualmente.

A Lei n 11.947/2009, instituiu as seguintes diretrizes da alimentação escolar: a) Alimentação saudável e adequada; b) Educação alimentar e nutricional; c) Universalização; d) Participação social; e) Promoção do desenvolvimento sustentável; e f) Direito à alimentação escolar (Brasil, 2009).

Bem como, as atualizações ocorridas nas legislações que regem o programa proporcionou a extensão de abrangência do programa para todos os estudantes matriculados nas etapas da educação básica de escolas públicas, fílantrópicas e em entidades comunitárias, sem fins lucrativos, seguindo os princípios do Direito Humano à Alimentação Adequada (DHAA) e da Segurança Alimentar e Nutricional (SAN) (Brasil, 2015).

O PNAE é um programa de caráter universal, sendo considerado uma importante estratégia para a garantia do DHAA e para a concretização da SAN. O direito humano à alimentação consta no arcabouço jurídico brasileiro desde 1992, quando o país assinou o Pacto Internacional dos Direitos Econômicos, Sociais e Culturais. Como todo direito humano, ele é universal, indivisível, inalienável, interdependente e inter-relacionado à realização dos demais direitos humanos, cabendo ao Estado respeitá-lo, protegê-lo, promovê-lo e provê-lo (Abrandh, 2013).

A Organização das Nações Unidas para Alimentação e Agricultura (FAO), define que a garantia de segurança alimentar acontece "quando todas as pessoas, em todos os momentos, têm acesso físico, social e econômico a uma alimentação suficiente, segura e nutritiva que atenda às suas necessidades nutricionais e preferências alimentares para uma vida ativa e saudável". No Brasil, o conceito tem a visão mais abrangente que permite a melhor compreensão das inter-relações entre as dimensões de SAN: "direito de todos ao acesso regular e permanente a alimentos de qualidade, em quantidade suficiente, sem comprometer o acesso a outras necessidades essenciais, tendo como base práticas alimentares promotoras da saúde que respeitem a diversidade cultural, econômica e socialmente sustentável" (Tiborski, et al., 2018).

Esse programa tem por finalidade buscar suprir parte das necessidades nutricionais dos estudantes, durante o ano letivo, ou seja, durante a sua permanência no contexto escolar. Um aspecto favorável é que reduz de forma significativa a evasão escolar, e promove aos estudantes, a alimentação e hábitos saudáveis. É importante destacar que a alimentação escolar contribui também com o desenvolvimento local sustentável, devido às suas legislações trazerem como priorização a aquisição dos gêneros alimentícios do comércio e das comunidades locais. E a responsabilidade de sua execução é atribuída constitucionalmente a todos os entes federados, portanto, participam da sua execução vários atores sociais que fazem parte do contexto educacional, tais como, gestores públicos, professores, diretores de escola, pais de estudantes, sociedade civil organizada, nutricionistas, manipuladores de alimentos, agricultores familiares, conselheiros de alimentação escolar, entre outros (Brasil, 2015).

\subsection{Cenário atual do PNAE na pandemia COVID-19}

Em fevereiro de 2020 foi declarado situação de calamidade pública no Brasil, por meio da Portaria GM/MS nº 188/2020, após esse evento diversas medidas foram tomadas para o controle de contaminação pelo coronavírus, causador da COVID-19. Iniciou-se as suspensões de atividades presenciais nas instituições de ensino e com isso se iniciou também as 
preocupações com a garantia dos direitos dos estudantes ao ensino, bem como ao acesso à alimentação escolar de mais de 40 milhões de estudantes da educação básica, visto que, para alguns essa alimentação realizada na escola era a principal ou até a única refeição do dia.

O fechamento das escolas a partir de março/2020 devido à pandemia deixou um imenso contingente de estudantes sem acesso às refeições diárias fornecidas pelo PNAE, contribuindo para a insegurança alimentar e nutricional (InSAN) de muitos dos escolares e suas famílias. (Gurgel, et al., 2020).

A pandemia do COVID-19 ao redor do mundo revelou-se uma ameaça concreta e imediata nas questões da segurança alimentar e nutricional (SAN) de populações mais vulnerabilizadas. As populações em situação de fome crônica podem crescer drasticamente, resultando na condição de insegurança alimentar e nutricional (InSAN). Se tornando essencial os governantes priorizar a garantia das condições de sobrevivência para o enfrentamento das mudanças forçadas pela pandemia (Oliveira, et al., 2020).

Buscando mitigar essas preocupações e garantir esse direito da alimentação aos estudantes, bem como, manter o dever do Estado com a educação, por meio da Lei $n^{\circ} 13.987$ de 07/04/2020, regulamentada pela Resolução CD/FNDE ${ }^{\circ} 02$ de 09/04/2020, o governo federal alterou a legislação do programa, excepcionalmente durante o período de calamidade pandêmica, qual autorizou a distribuição de gêneros alimentícios aos estudantes e/ou responsáveis (Brasil, 2020). Assim, a execução dos recursos do PNAE pela maioria dos entes executores, passaram a ser destinados para aquisição de kits de alimentação (cesta básica) e os estudantes acessaram a política por meio do recebimento desses.

Cabe salientar que os normativos que regulamentam a execução dessa política durante a pandemia, ressaltam que a composição desses kits alimentação devem seguir os princípios do PNAE na oferta de alimentação saudável e adequada, que respeite as questões biológicas entre as idades e as condições de saúde do estudante. Que os alimentos ofertados tenham qualidade sanitária e apresentem valor nutricional, assim, buscando montar os kits com alimentos básicos (arroz, feijão, entre outros) e alimentos in natura (frutas, verduras, legumes, proteínas animal), evitando ao máximo os alimentos processados. Bem como, que na montagem desses kits se observe as questões dos hábitos alimentares e culturais da região.

Sperandio \& Morais (2021) retrata que a maioria das Entidades Executoras tem distribuído cestas básicas prontas, comercializadas no mercado, e não montadas seguindo os princípios e recomendações do PNAE. Em algumas localidades do país as Entidades Executoras optaram pela distribuição de “cartões cesta” para que as famílias pudessem retirar a cesta básica no comércio local.

Portal, et al., (2021) destaca que em todo o Brasil, as estratégias adotadas pelas Entidades Executoras foram muito heterogêneas, embora as orientações e normas tenham sido direcionadas a todo o país, a melhor forma de manter a alimentação escolar durante a suspensão das aulas presenciais caberia à gestão local. Algumas estratégias implementadas no país foram ao encontro da legislação nacional e orientações do FNDE, outras não seguiram o recomendado, optando pela compra centralizada, sem observar a legislação que rege o mínimo de $30 \%$ dos recursos que devem ser de produtos da agricultura familiar. Como também, trouxe que os recursos do programa não foram suficientes para atender todos os alunos, foi necessário fazer uso de outros recursos como da assistência estudantil e da campanha solidária, ainda assim, precisou fazer recorte social para atendimento aos alunos mais vulneráveis socioeconomicamente.

Se faz necessário refletir a respeito de dois princípios do PNAE que se apresentam desafiadores neste período de pandemia, os princípios da universalidade do atendimento e o apoio ao desenvolvimento sustentável, visto que, o programa é de caráter universal e que às suas legislações trazem como priorização a aquisição dos gêneros alimentícios da agricultura familiar e das comunidades locais.

Bicalho \& Lima (2020) expõem que o PNAE é um elemento de fortalecimento e garantia de renda para os agricultores 
familiares, além de promover uma alimentação adequada e saudável para os estudantes em suas casas. A articulação entre as políticas de educação e de agricultura para a entrega dos kits de alimentos para os estudantes é uma estratégia importante para reduzir os impactos negativos da pandemia tanto na alimentação escolar quanto na agricultura familiar.

No estudo realizado por Dos Santos, et al., (2021) aponta que a suspensão das aulas, como forma de controle da COVID-19 no Brasil, afetou diretamente o PNAE e reforçou a insegurança alimentar de estudantes e agricultores familiares que forneciam para a alimentação escolar em municípios do Piauí. Bem como, concluí que foram identificados como fatores limitantes à execução do PNAE a redução na compra de gêneros da agricultura familiar pelas Entidades Executoras, comprometimento da quantidade e qualidade dos alimentos fornecidos e o cumprimento do direito à alimentação escolar.

O Observatório da Alimentação Escolar - ÓAÊ (2021) realizou uma pesquisa junto aos estudantes do Brasil e constatou que durante a pandemia, o direito dos estudantes de receber a alimentação escolar não está sendo assegurado, e que é significativo o percentual de estudantes que não recebeu nenhum tipo de assistência alimentar, desde a suspensão das aulas, ou que recebeu uma única vez.

Sendo retratada essa tese também no estudo de Sperandio \& Morais (2021) que traz que a não oferta da alimentação escolar para todos os estudantes matriculados na rede pública de ensino contraria o princípio do programa da universalidade. Ressalta que a utilização de um critério socioeconômico para recorte de público-alvo a ser beneficiado pelo PNAE nesse momento de pandemia, representa uma flexibilização desse princípio, o qual não deveria acontecer, pois o PNAE é parte de uma Política Nacional de Educação que tem caráter universal e todos os estudantes da educação básica possuem o direito de acessar a política.

Segundo Alpino, et al., (2020) este momento da pandemia coloca em foco o maior problema do Brasil, as desigualdades sociais, e essas que agravam os efeitos da COVID-19 nas condições de vida da população. Se faz necessário que o Estado reconheça a extensão das desigualdades sociais como um obstáculo para o desenvolvimento, e reorganize as políticas econômicas do país priorizando as questões que proporcionem a proteção social, pois o modelo econômico dominante criou condições propícias para a insegurança alimentar e o aumento da pobreza (Paula \& Zimmermann, 2021).

Além das adaptações que ocorreram durante a situação pandêmica, ocorreram também alterações nas regulamentações do programa, a promulgação da Resolução FNDE/MEC n ${ }^{\circ} 06$ de 08 de maio de 2020, seguida da Resolução FNDE/MEC nº 20 de 02 de dezembro de 2020, que determinam as regras de execução do PNAE a partir de 2021, sendo revogadas as Resoluções FNDE/MEC n ${ }^{\circ}$ 26/2013 e n $^{\circ}$ 04/2015, proporcionando alterações importantes nos quesitos da qualidade nutricional dos cardápios e a aplicação de penalidade às Entidades Executoras que não atenderem ao mínimo obrigatório de gastos com a agricultura familiar. Essas inovações em plena situação de calamidade pública e cenário de crise podem ser consideradas como fortalecimento e melhoria na continuidade do PNAE.

\section{Conclusão}

Sabendo que o PNAE é uma política pública que tem por objetivo contribuir para o crescimento e o desenvolvimento biopsicossocial, a aprendizagem, o rendimento escolar e a formação de hábitos saudáveis dos estudantes, a elaboração desta revisão pode contribuir para a compreensão da política e ressaltar a importância dela no contexto educacional e social do país.

Bem como, proporcionar reflexões sobre o quanto essa política precisa ser vista e valorizada pelos governantes e pela sociedade civil. O PNAE é reconhecido internacionalmente por ser um dos principais programas que contribui com o Direito Humano à Alimentação Adequada e com a Segurança Alimentar e Nutricional, e neste período de calamidade pública o 
programa se torna ainda mais importante no enfrentamento da fome e das desigualdades sociais. Portanto, se faz necessário que a sociedade exija dos governantes e das entidades executoras que o programa seja executado em sua integralidade.

Ressalta-se que este estudo trouxe um contexto introdutório da atual situação legal e de execução dessa política pública, faz-se necessário outros estudos de modo mais abrangentes e/ou até específicos dentro de instituições de ensino nas quais envolvam os executores e os beneficiários do programa.

\section{Referências}

Abrandh. (2013). O direito humano à alimentação adequada e o sistema nacional de segurança alimentar e nutricional / organizadora Marília Leão. Brasília $-\mathrm{DF}$.

Alpino, et al. (2020). COVID-19 e (in)segurança alimentar e nutricional: ações do Governo Federal brasileiro na pandemia frente aos desmontes orçamentários e institucionais. Cad. Saúde Pública 2020; 36(8):e00161320. DOI: 10.1590/0102-311X00161320

Amorim, et al. (2020). Programa Nacional de Alimentação Escolar: estratégias para enfrentar a insegurança alimentar durante e após a COVID-19. Revista de Administração Pública - RAP. Rio de Janeiro 54(4):1134-1145, jul. - ago. 2020. DOI: http://dx.doi.org/10.1590/0034-761220200349

Bicalho, D. \& Lima, T. M. (2020). O Programa Nacional de Alimentação Escolar como garantia do direito à alimentação no período da pandemia da COVID19. DEMETRA: Alimentação, Nutrição \& Saúde. 15, e52076. ISSN 2238-913X. DOI: https://doi.org/10.12957/demetra.2020.52076.

Brasil. (1988). Constituição Federal da República. Brasília - DF.

Brasil. (2006). Lei $\mathrm{N}^{\circ} 11.346$ de 15 de setembro de 2006. Brasília - DF.

Brasil. (2009). Lei no 11.947, de 16 de junho de 2009. Presidência da República, Brasília - DF.

Brasil. (2015). Cartilha Nacional da Alimentação Escolar. 2ª edição. Ministério da Educação - FNDE. Brasília - DF.

Brasil. (2020). Lei n 13.987 , de 07 de abril de 2020. Presidência da República, Brasília - DF.

Brasil. (2020). Resolução/CD/FNDE nº 2, de 9 de abril de 2020. Ministério da Educação - FNDE, Brasília - DF.

Brasil. (2020). Orientações para a execução do PNAE durante a situação de emergência decorrente da pandemia do coronavírus (COVID-19). $1^{\mathrm{a}}$ edição. Ministério da Agricultura, Pecuária e Abastecimento. Brasília - DF.

Dos Santos, et al. (2021). Pandemia da COVID-19 e seus reflexos na manutenção da Alimentação Escolar em municípios Piauienses. Revista Agricultura Familiar: Pesquisa, Formação e Desenvolvimento. Belém. 15, 221-226. DOI: http://dx.doi.org/10.18542/raf.v15i1.9951.

Fonseca, J. J. S. da. (2002). Metodologia da pesquisa científica. UECE.

Fundo Nacional de Desenvolvimento da Educação - FNDE. (2021). Programa Nacional de Alimentação Escolar. Disponível em: https://www.gov.br/fnde/ptbr/acesso-a-informacao/acoes-e-programas/programas/pnae.

Gurgel, et al. (2020). Estratégias governamentais para a garantia do direito humano à alimentação adequada e saudável no enfrentamento à pandemia de COVID-19 no Brasil. Ciência \& Saúde Coletiva, 25(12):4945-4956. DOI: 10.1590/1413-812320202512.33912020.

Koche, J. C. (2011). Fundamentos de metodologia científica. Petrópolis. Vozes. http://www.adm.ufrpe.br/sites/ww4.deinfo.ufrpe.br/files/ Fundamentos_de_Metodologia_Cienti\%CC\%81fica.pdf

Observatório da Alimentação Escolar- ÓAÊ. (2021). Estudantes - O que pensamos os/as escolares sobre o Programa Nacional de Alimentação Escolar, antes e na pandemia de COVID-19. Disponível em: https://alimentacaoescolar.org.br/media/acervo/documentos/LEVANTA_DADOS_ESTUDANTE_VF.pdf.

Oliveira, et al. (2020). (In)Segurança alimentar no contexto da pandemia por SARS-CoV-2. Cad Saúde Pública 2020; 36(4):e00055220. DOI: 10.1590/0102$311 \mathrm{X} 00055220$.

Paula, N. M. \& Zimmermann, S. A. (2021). A insegurança alimentar no contexto da pandemia da COVID-19 no Brasil. Revista NECAT. 10(19), 55-66. https://revistanecat.ufsc.br/index.php/revistanecat/article/view/4849.

Portal, et al. (2021). Alimentação escolar no contexto da pandemia COVID - 19 nas Instituições Federais de Ensino da Região Metropolitana de Belém/Pará. Revista Agricultura Familiar: Pesquisa, Formação e Desenvolvimento. Belém. 15, 175-195. Disponível em: http://dx.doi.org/10.18542/raf.v15i1.9798. 
Research, Society and Development, v. 10, n. 12, e384101220693, 2021

(CC BY 4.0) | ISSN 2525-3409 | DOI: http://dx.doi.org/10.33448/rsd-v10i12.20693

Sperandio, N. \& Morais, D. de C. (2021). Alimentação escolar no contexto de pandemia: a ressignificação e o protagonismo do Programa Nacional de Alimentação Escolar. Segur.Aliment. Nutr., Campinas, 28, 1-11. e021006. DOI: http://dx.doi.org/10.20396/san.v28i00.8661396.

Tiborski, et al. (2018). Alimentação escolar no Brasil e Estados Unidos: uma revisão integrativa. Ciênc. saúde colet. 23 (3). Disponível em: https://doi.org/10.1590/1413-81232018233.01582016. 